\title{
A New MATLAB GUI Tool for Instructing Operation of Power Electronic Rectifiers
}

\author{
Mohammadreza Modabbernia1, Seyed Yaser Fakhrmoosavi1 ${ }^{1}$, \\ Alireza Akoushideh ${ }^{1}$ and Alireza Ahadpour Shal ${ }^{2}$
}

\author{
${ }^{1}$ Department of Electrical Engineering, Technical and Vocational University, \\ Rasht Branch, Rasht, Iran. \\ 2Department of Electronic Engineering, Faculty of Engineering, Lahijan Branch, \\ Islamic Azad University, P.O. Box 1616, Lahijan, Iran \\ E-mail:mmodabernia@tvu.ac.ir, Dr.fakhrmoosavi@tvu.ac.ir, \\ aakoushideh@tvu.ac.ir, a_ahadpour@liau.ac.ir
}

Received February 12, 2019; Revised March 25, 2019; Accepted May 18, 2019

\begin{abstract}
This study seeks to present an interactive tool, which exploits the GUI related abilities in MATLAB, to investigate power electronic rectifiers operation. In this paper, instead of using the various equations for one particular type of rectifier, some basic equations are proposed for current of all kinds of controlled and uncontrolled, single and threephase rectifiers with or without flywheel diode and R, L, E loads and their combinations by changing some parameters. Furthermore, a flexible and extendable environment has been introduced for steadystate simulation of these power electronic rectifiers. The easy usage of our tool and equations make them feasible to be used by the teacher in the classroom. Also, the short running time of the program and the PSpice output netlist make it a remarkable alternative to the MATLAB PowerSim toolbox and PSIM software for studying ac-dc converters. The performance and accuracy of the proposed equations, MATLAB functions, and GUI environment have been shown by simulation of some practical examples which are studied in the reference books. Comparing the simulation results of the proposed program with the PSpice and theoretical results of the reference books show the merit of it.
\end{abstract}

Keywords: ac-dc converters, power electronic rectifier, MATLAB GUI, PSpice, interactive program

\section{INTRODUCTION}

One of the most significant social development indicators is education from which the communities, economy and industry can benefit. In recent 
decades, in parallel with computer sophistication, some new remedies are introduced for educational resource expansion and scientists have introduced different techniques, tools and methods in order to optimize teaching methods [1-2].

By utilizing an interactive computer-based method, it can be more effective to persuade students to cooperate in achievement of educational objectives [3]. This is remarkably useful in curriculums that deal with expensive laboratories because in most cases, students are not able to observe some basic and simple experiences and tests. Not only does power electronic deal with expensive laboratorial equipment, but also with high power voltages and currents so that utilizing a convenient method which uses computer abilities can make theoretical subjects tangible for students, and; consequently, can remarkably help promote education of power electronic curriculums.

On the other hand, the proper understanding of power electronic circuits operation rests on a clear comprehension of transient behavior of voltage and current waveforms. In the investigation of power electronic circuits, the achievement to the system transient behavior raises the need for solving some differential equations with initial values. In this regard, the power electronic system has become a difficult and challenging subject for students and have a user-friendly program could help them easily.

In recent years, some tools have been developed by researchers in order to assist students to learn how basic power electronic circuits operate. For instance, thyristor characteristic curve and single-phase pulse width modulator convertor have been proposed in [4]. Also, based on the Spice thyristor model in [5], the single-phase and three-phase cyclo-converters have been simulated in PSpice environment [6]. In [7] a full-bridge convertor, a DC to DC convertor and a full controlled 3-phase full-wave rectifier with resistive load have been stimulated. Utilizing MATLAB capabilities, a new tool is presented for power system simulation in [8]. Further, JAVA has been introduced as a conventional basis for expansion of needed tools for single and three-phase rectifier simulation [9-13] and based on that a program has been developed which is able to simulate controlled and uncontrolled single and three-phase rectifier considering their theoretical equations [14]. One of the prominent imperfections of latest mentioned program was its inability to consider back electromotive force $(E)$ as a load which, in this proposed program, it has been taken into account. By combining the theoretical analysis, simulation and experimental results of power electronics circuits, an active learning methodology is designed in [15]. a novel online simulator which is integrated by the educational project iPES, -Interactive Power Electronics Seminar- has been presented based on Java applets for educational targets [16]. In [17] a complete photovoltaic solar generation power system has been introduced for incorporating all basic power electronic conversions.

Having different loads, being single-phase or three-phase, being controlled or uncontrolled and also having flywheel diode or not, there can be a variety of power electronic rectifiers. This variation makes it difficult for 
students understand the mechanism of different voltage and current waveforms creation specifically in controlled-rectifiers. In the case of presenting all rectifiers output waveforms in 2 or 3 general equation which can be transformed to each other, students can be expected to understand circuit operation and also state the output voltage and current waveforms. In this paper it is shown that by definition of a new parameter which is referred to as "output voltage waveform period" $(T)$, it is possible to state current equation in transformable form for both single-phase and three-phase rectifiers. Consequently, this can be considered as an important educational highlight of power rectifiers. Furthermore, some $\mathrm{m}$-files are presented for estimating efficiency parameters of rectifiers. These $\mathrm{m}$ files can be easily applied into other programs of MATLAB and can be developed for other applications. Also, there is the capability of promoting them to other $m$ files for other applications. Based on these M-files and GUI ability of MATLAB, an interactive tool is presented. Students can easily use this tool without any further specialism by giving rectifier parameters like; load values, input values and controlling angle and probing output waveforms and efficiency parameters. This program automatically produces a text file (.cir) of simulated circuit in PSpice format which can be run in PSpice A/D program. Finally, single-phase and three-phase rectifiers which are analyzed theoretically in [18-19] are chosen to be simulated to investigate accuracy and correctness of the proposed program. Comparison among simulated results, theoretical results and results obtained from PSpice simulation verify proposed program accuracy.

It should be mentioned that definable circuits in proposed program can be created by PowerSim blocks in MATLAB, but they are complicated. The above-said definable circuits whose main applicable are different need an adequate level of competency. All in all, these aspects make PowerSim improper in basic educational experiences. In the other words, the simplicity of proposed tool in this paper is one of its advantages.

The main contributions of the paper are: (i) Introducing an equation for the load current of all types of the rectifiers with the R, L, E loads and their combinations. (ii) Development of some MATLAB M-files for calculating the rectifier's characteristics. (iii) presenting a program for analyzing and simulation of power electronics rectifiers with PSpice netlist output based on MATLAB GUI environment.

The rest of this paper has been organized as follows: in section 2, some basic equations are introduced to analyze the load current of controlled and uncontrolled, single and three-phase rectifiers with or without flywheel diode and R, L, E loads and their combinations by changing some parameters. How to calculate of the thyristor's turning off angle is given in section 3. Also, in this section, some MATLAB M-files are expanded for calculation of the rectifiers characteristics. Based on the proposed M-Files and MATLAB GUI capabilities, an interactive environment has been introduced for analyzing the power electronics rectifiers in section 4 . Section 5 deals with the evaluation of the 
program performance by means of simulations some practical examples which are studied in the reference books [15-19].

\section{CURRENT EQUATIONS OF RECTIFIERS}

From students' educational point of view, the vast variation of ac to dc convertors makes their acquisition hard to learn. Rectifiers can be divided into two general structures comprising "single-phase" and "three-phase" which can be utilized as "half-wave" and "full-wave" respectively. In half-wave structure, convertors can be divided into controlled and uncontrolled convertors and in full-wave structures they can be divided into controlled, uncontrolled and halfcontrolled convertors. All mentioned circuits can be with or without flywheel diode. Figures 1 through 4 show the power circuits of the controlled singlephase half-wave rectifier, controlled single-phase full-wave rectifier, controlled 3-phase half-wave rectifier, and controlled 3-phase full-wave rectifier respectively.

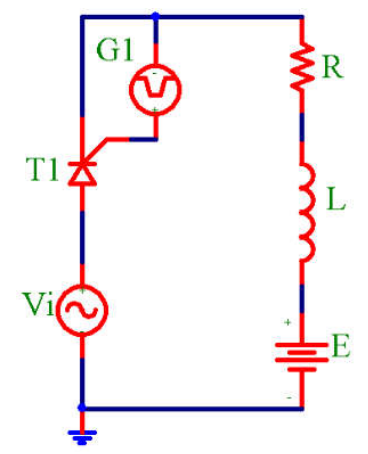

a) Without flywheel diode

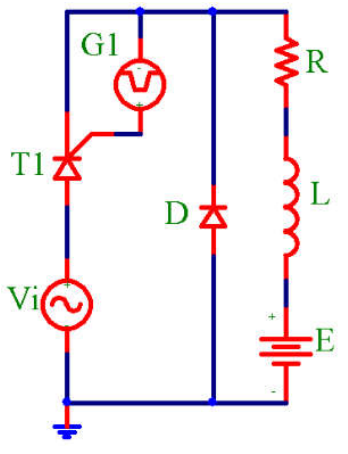

b) With flywheel diode

Figure 1. the controlled single-phase half-wave rectifier

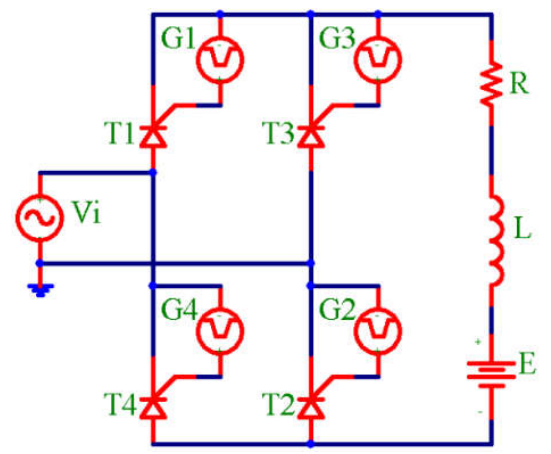

c) Without flywheel diode

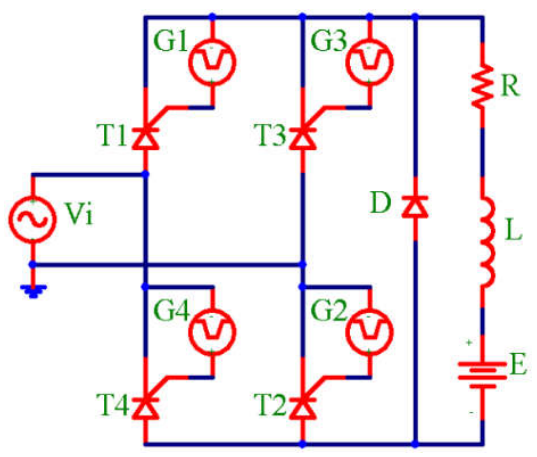

d) With flywheel diode

Figure 2. the controlled single-phase full-wave rectifier 


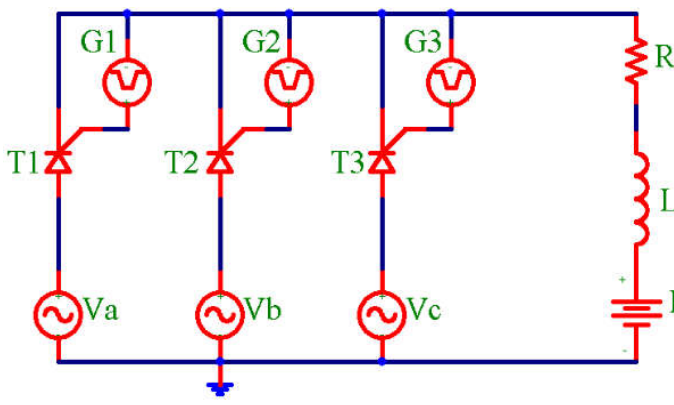

a) Without flywheel diode

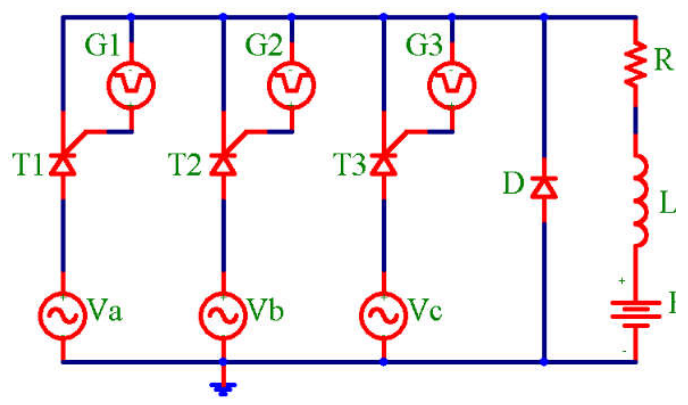

b) With flywheel diode

Figure 3. the controlled 3-phase half-wave rectifier

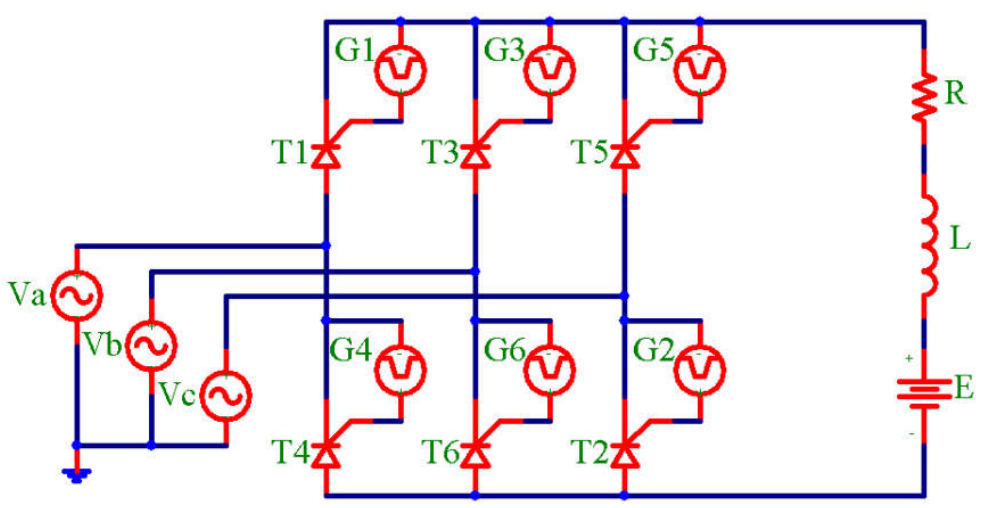

a) Without flywheel diode

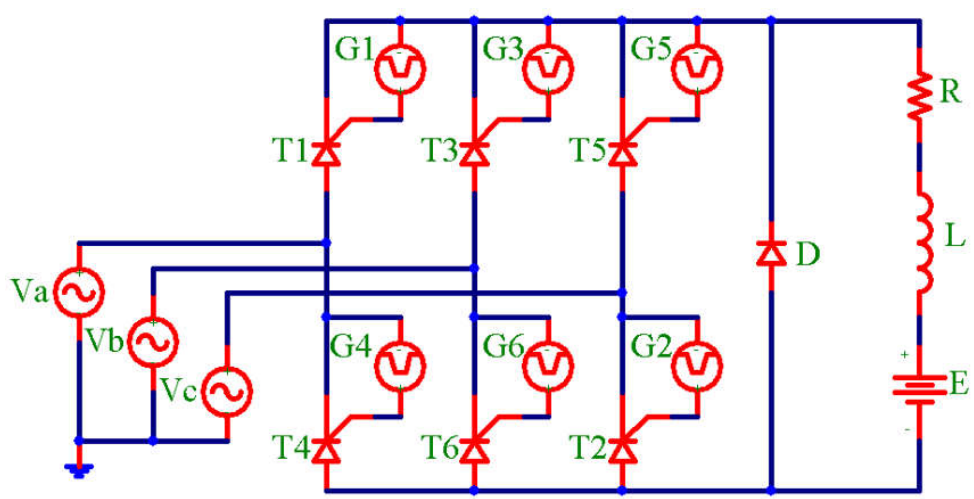

b) With flywheel diode

Figure 4. the controlled 3-phase full-wave rectifier

Another educational hardship in this subject is variation of loads in each circuit. A rectifier load can be any desired combination of pure resistive $(R)$, Inductive $(L)$ and back electromotive force $(E)$ loads. So, students are dealing 
with numbers of different circuits in which according to rectifier type, load characteristics and presence or absence of flywheel diode, variety of condition are provided for analysis variation

A crucial point in rectifiers' analysis is definition of continuity or discontinuity of load current that can form the general shape of output waveform. This definition is rests on turn-off angle of the circuit which in turn this angle calculation is possible in the case of having load current equation. Somehow it can be said that the educational problem in this subject has its root in this crucial point because various reference books have presented various non-identical equations for just some specific rectifiers and loads [15-19]. As a result, students are encountered with variety of equations that make the acquisition to appear more complicated

If it is possible to present all different equations of load current in a unique and general format which can be simply transformed into specific cases, an influential development will happen in power electronic rectifiers teaching methods. In all kinds of single and three-phase rectifiers with R-L-E load and without flywheel diode, when one or two keys (based on the kind of rectifier) have been turned on until the current flow through the load, we have a RL first order circuit with sinusoidal input $\left(V_{m} \sin (\omega t)\right.$ or $\sqrt{3} V_{m} \sin (\omega t+\pi / 6)$ ) and initial condition $i_{L}\left(\omega t=\alpha^{\prime}\right)=0$. $\alpha^{\prime}$ is the turning on angle of the thyristors. The equations (1) through (3) define the differential equations of this R-L-E circuit in four power electronics rectifiers of figures (1-a), (2-a), (3a), and (4-a), respectively. The controlled single-phase half-wave rectifier (figure (1-a)) and controlled single-phase full-wave rectifier (figure (2-a)) have the same differential equation.

$$
\begin{aligned}
& \left\{\begin{array}{c}
L \frac{d i_{L}}{d t}+R i_{L}+E=V_{m} \sin (\omega t) \\
i_{L}(\omega t=\alpha)=I_{\text {min }}
\end{array}\right. \\
& \left\{\begin{array}{c}
L \frac{d i_{L}}{d t}+R i_{L}+E=V_{m} \sin (\omega t) \\
i_{L}\left(\omega t=\alpha+\frac{\pi}{6}\right)=I_{\text {min }}
\end{array}\right. \\
& \left\{\begin{array}{c}
L \frac{d i_{L}}{d t}+R i_{L}+E=\sqrt{3} V_{m} \sin \left(\omega t+\frac{\pi}{6}\right) \\
i_{L}\left(\omega t=\alpha+\frac{\pi}{3}\right)=I_{\min }
\end{array}\right.
\end{aligned}
$$

By defining the rectification parameters of four different kinds of the rectifiers as Table. 1, the differential equations (1) through (3) could be aggregated as equation (4). 
$\left\{\begin{array}{c}L \frac{d i_{L}}{d t^{\prime}}+R i_{L}+E=V_{m}^{\prime} \sin \left(\omega t^{\prime}\right) \\ i_{L}\left(\omega t^{\prime}=\alpha^{\prime}\right)=I_{\text {min }}\end{array}\right.$

By assumption, the continuous load current and solving the differential equation (4) by the minimum current $I\left(\omega t^{\prime}=\alpha^{\prime}\right)=I\left(\omega t^{\prime}=T+\alpha^{\prime}\right)=I_{\min }$, the general load current equation for all kinds of the single and three-phase rectifiers with R-L-E load and without flywheel diode could be achieved as:

$Z=\sqrt{R^{2}+L^{2} \omega^{2}}$

$\varphi=\tan ^{-1}\left(\frac{L \omega}{R}\right)$

$I_{\text {min }}=\frac{V_{m}^{\prime}}{Z}\left\{\frac{\sin \left(T+\alpha^{\prime}-\varphi\right)-\sin \left(\alpha^{\prime}-\varphi\right) e^{\frac{-R}{L \omega} T}}{1-e^{\frac{-R}{L \omega} T}}\right\}-\frac{E}{R}$

$i_{L}\left(\omega t^{\prime}\right)=\frac{V_{m}^{\prime}}{Z} \sin \left(\omega t^{\prime}-\varphi\right)+\left[I_{\min }+\frac{E}{R}-\frac{V_{m}^{\prime}}{Z} \sin \left(\alpha^{\prime}-\varphi\right)\right] e^{\frac{-R}{L \omega}\left(\omega t^{\prime}-\alpha^{\prime}\right)}-\frac{E}{R}$

If load current is discontinuous instead of utilizing equation (7), $I_{\min }$ will be zero. By selecting proper values for $T, V_{m}^{\prime}, \alpha^{\prime}$ and $\omega t^{\prime}$ it will be possible to extend above mentioned equations for all kinds of single and three-phase rectifiers. Table 1 represents appropriate values of these parameters for different kinds of rectifiers.

Table 1. Rectification parameters of different kind of rectifiers.

\begin{tabular}{|c|c|c|c|c|c|}
\hline kind of rectifier & $\omega t^{\prime}$ & $\alpha^{\prime}$ & $V_{m}^{\prime}$ & $T$ & $\beta$ \\
\hline Controlled Single-Phase Half-wave & $\omega t$ & $\alpha$ & $V_{m}$ & $2 \pi$ & $\beta$ \\
\hline Controlled Single-Phase Full-wave & $\omega t$ & $\alpha$ & $V_{m}$ & $\pi$ & $\beta$ \\
\hline Controlled Three-Phase Half-wave & $\omega t$ & $\alpha+\frac{\pi}{6}$ & $V_{m}$ & $\frac{2 \pi}{3}$ & $\beta$ \\
\hline Controlled Three-Phase Full-wave & $\omega t+\frac{\pi}{6}$ & $\alpha+\frac{\pi}{3}$ & $\sqrt{3} V_{m}$ & $\frac{\pi}{6}$ & $\beta+\frac{\pi}{6}$ \\
\hline
\end{tabular}

If there is a flywheel diode in circuits, load current equation will have two parts. In first part, where, load current equations are equation (5), (6) and (8) and $I_{\min }$ can be obtained from equation (9). In second part, where 
inductive current discharge via flywheel diode starts, according to equation (10) and equation (11).

$$
\begin{aligned}
& I_{\text {min }}=-\frac{E}{R}+\left[I(0)+\frac{E}{R}\right] e^{\frac{-R}{L \omega}\left(T-\pi+\alpha^{\prime}\right)} \\
& i_{L 2}\left(\omega t^{\prime}\right)=-\frac{E}{R}+\left[I(0)+\frac{E}{R}\right] e^{\frac{-R}{L \omega}\left(\omega t^{\prime}-\pi\right)} \\
& I(0)=\frac{\frac{V_{m}^{\prime}}{Z} \sin (\pi-\varphi)-\frac{V_{m}^{\prime}}{Z} \sin \left(\alpha^{\prime}-\varphi\right) \mathrm{e}^{\frac{-R}{L \omega}\left(\pi-\alpha^{\prime}\right)}}{1-\mathrm{e}^{\frac{-R}{L \omega} T}}
\end{aligned}
$$

\section{PREPARED M-FILES IN MATLAB}

In rectifiers' analysis, definition of turn-off angle $(\beta)$ is very important. Negligence in consideration of the $\beta$ value results is mistaken solving of the given problem. Because in continuous current condition the effects of back electromotive force is not seen on the load voltage and as a result, all waveforms and rectification parameters will be incorrectly altered. For example, in problem no. 5-15 in [18], a controlled single phase full wave rectifier which has $\alpha=\pi / 3, R=10 \Omega, L=20 \mathrm{mH}$ and $E=10 \mathrm{~V}$ with a flywheel diode is supposed to has a continuous current and then is solved. While, with this given information theoretically $\beta=212.25^{\circ}$ and load current is discontinuous. So that initial assumption is wrong. Figure 5 illustrates PSpice simulated output waveforms of this circuit with $\beta=209.754^{\circ}$ and discontinuous load current. 


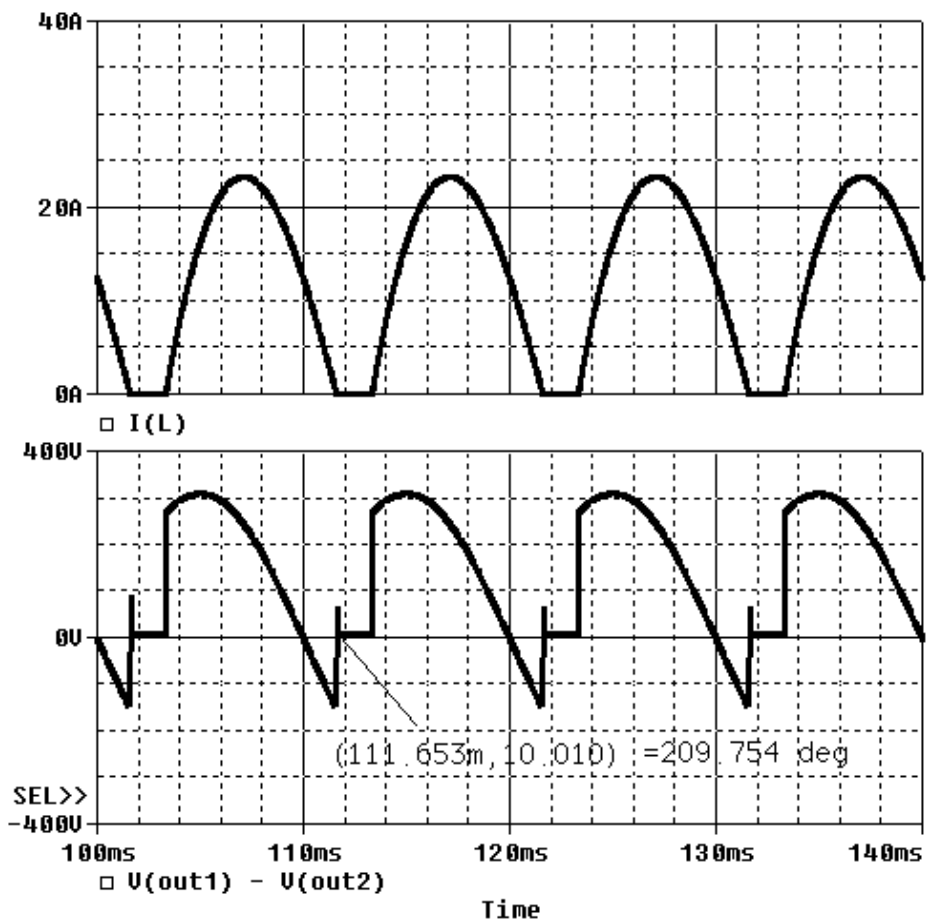

Figure 5. Pspice simulation results for the circuit of problem no. 5-15 in [18]

Turn-off angle is the value of angular velocity $(\omega t)$, wherein current flow of thyristor or flywheel diode is less than $I_{\text {hold }}$ (ideal value of $I_{\text {hold }}$ is zero). Based on this assumption and also equating equations (4) and (5) with the value of $I_{\text {hold }}$, below mentioned states can be achieved for $\beta$ definition:

State $A$ ) If there is pure resistive load, turn-off angle in single-phase half and full-wave rectifier and also three-phase half-wave rectifier is $\omega t^{\prime}=\omega t=\pi$ and for three-phase full-wave one is

$$
\omega t^{\prime}=\omega t+\frac{\pi}{6}=\pi \Rightarrow \omega t=\frac{5 \pi}{6}
$$

State B) If there is no flywheel diode, by solving equation (8) which is nonlinear, $\beta$ can be calculated (even by a calculator). In discontinuous condition $I_{\min }$ is zero and $V_{m}^{\prime}, \alpha^{\prime}$, and $\beta^{\prime}$ are selected from data of Table 1. This equation gives $\beta$ with respect to $\omega t=0$

$$
\frac{V_{m}^{\prime}}{Z} \sin \left(\beta^{\prime}-\varphi\right)+\left[\frac{E}{R}-\frac{V_{m}^{\prime}}{Z} \sin \left(\alpha^{\prime}-\varphi\right)\right] e^{\frac{-R}{L \omega}\left(\beta^{\prime}-\alpha^{\prime}\right)}-\frac{E}{R}-I_{\text {hold }}=0
$$

State $C$ ) If there is flywheel diode in the circuit, there are different relations depending on $\mathrm{E}$ value 
if $E=0 \Rightarrow \begin{cases}\beta=\pi+\frac{5 L \omega}{R} & \text { for 1-phase or 3-phase half-wave rectifier } \\ \beta=\frac{5 \pi}{6}+\frac{5 L \omega}{R} & \text { for 3-phase full-wave rectifier }\end{cases}$

if $E>0 \Rightarrow\left\{\begin{array}{l}\beta=\pi+\frac{L \omega}{R} \ln \left[\frac{R I(0)+E}{R I_{\text {hold }}+E}\right] \\ \beta=\frac{5 \pi}{6}+\frac{L \omega}{R} \ln \left[\frac{R I(0)+E}{R I_{\text {hold }}+E}\right]\end{array}\right.$

if $E<0 \Rightarrow$ Load Current is Continuous

State $D)$ The negative value of $I(0)$ in state $C$ shows that flywheel diode will never turn on and so that $\beta$ should be calculated from state $B$.

In order to investigate all single and three-phase rectifiers and calculate their efficiency parameters and output harmonics, five m-files has been written in Matlab. These files have been utilized to prepare a conversational environment for simulation of power electronic rectifier circuits.

Main applicable file is "rectifier.m" that gives turn-off angle, current and voltage vectors of different nodes in circuit. Each of mentioned output can be plotted by "plot.m" instruction in MATLAB. Moreover, utilizing this instruction's outputs accompanied by "rms.m", "av.m", "rectfour.m" and "rectparam.m" functions, all efficiency parameters and harmonics of rectifier circuit can be estimated. In order to get information of how to use these functions ".help" instruction is available.

\section{- M-file for Turn-off Angle Calculation}

The main m-file is "rectifier.m". The general format of this m-file is as below and its inputs and outputs are listed in Table 2 and 3 respectively.

[Betadeg, Betarad, wt, vwt, iwt, vtwt, itwt, iawt, vdwt, idwt] $=$ rectifier(vm, R, L, E, f , a , T, Ihold, diode)

Table 2. Input variables of "rectifier.m" m-file.

\begin{tabular}{|c|c|}
\hline Input Variable & Description \\
\hline $\mathrm{vm}$ & The peak value of Single-phase Input Voltage \\
\hline $\mathrm{R}$ & The value of pure resistive load \\
\hline $\mathrm{L}$ & The value of inductive load \\
\hline $\mathrm{E}$ & The value of back electromotive force \\
\hline $\mathrm{f}$ & The frequency of input waveform \\
\hline $\mathrm{a}$ & Gate firing angle \\
\hline $\mathrm{T}$ & $\begin{array}{l}\text { The period of output rectified waveform } \\
\text { 1-phase half-wave : } \mathrm{T}=360 \\
\text { 1-phase full-wave : } \mathrm{T}=180 \\
\text { 3-phase half-wave }: \mathrm{T}=120 \\
\text { 3-phase full-wave : } \mathrm{T}=60\end{array}$ \\
\hline Ihold & Minimum value for continuous current \\
\hline diode & Represent presence of flywheel diode \\
\hline
\end{tabular}




\begin{tabular}{|l|l|}
\hline & $\begin{array}{l}\text { diode=0 }: \text { no flywheel diode } \\
\text { diode=1: flywheel diode } \\
\text { diode=2 }: 3 \text {-phase half controlled-rectifier }\end{array}$ \\
\hline
\end{tabular}

Table 3. Output variables of "rectifier.m" m-file.

\begin{tabular}{|l|l|}
\hline Output Variable & Description \\
\hline wt & Output angle vector in degree \\
\hline iwt, vwt & Current and voltage vector \\
\hline itwt, vtwt & Current and voltage vector of Thyristor.1 \\
\hline iawt & Current vector of phase a \\
\hline idwt, vdwt & Current and voltage vector of flywheel diode \\
\hline Betarad, betadeg & Turn-off angle in radian and degree \\
\hline
\end{tabular}

\section{- M-file for Average and rms Current and Voltage Calculation}

General format of the functions is as below in which inputs are identical to "rectifier.m" function and only the input"Beta" is the output of "Betadeg" from "rectifier.m" function.

$[\operatorname{Vav}, \operatorname{Idc}, \operatorname{IavT}, \operatorname{IavD}, \operatorname{IavA}]=\mathrm{av}(\mathrm{vm}, \mathrm{R}, \mathrm{L}, \mathrm{E}, \mathrm{f}, \mathrm{a}$, beta, $\mathrm{T}$, diode $)$

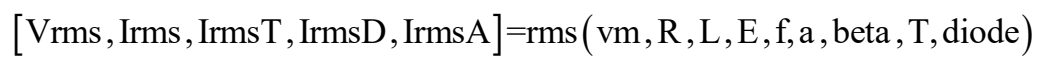

The outputs of this function are listed in Table 4 .

\section{- M-file for Output Harmonic Calculation}

The name of m-file is "rectfour.m" and its general format is [DC, a , b , mag, phase, $\mathrm{ff}, \mathrm{cl}, \mathrm{cn}$, phil, maximum $]=$ rect four $($ input $, \mathrm{wt}, \mathrm{f}, \mathrm{semi}, \mathrm{ia}, \mathrm{n})$

Table 4. Output variables of "av.m" and "rms.m" m-files.

\begin{tabular}{|l|l|}
\hline Output Variable & Description \\
\hline Vav, Vrms & Average and rms value of load voltage \\
\hline Idc, Irms & Average and rms value of load current \\
\hline IavT, IrmsT & Average and rms value of Thyristor no.1 current \\
\hline IavD, IrmsD & Average and rms value of Flywheel Diode current \\
\hline IavA, IrmsA & Average and rms value of phase a current \\
\hline
\end{tabular}

In which the inputs and outputs of "rectfour.m" function are listed in Table 5 and 6 respectively.

Table 5. Input variables of "rectfour.m" m-file.

\begin{tabular}{|l|l|}
\hline Input Variable & Description \\
\hline input & $\begin{array}{l}\text { It can be vwt, iwt, itwt or iawt resulted from "rectifier.m" } \\
\text { function }\end{array}$ \\
\hline
\end{tabular}




\begin{tabular}{|l|l|}
\hline wt & Angle vector resulted from "rectifier.m" function \\
\hline $\mathrm{f}(\mathrm{Hz})$ & Input waveform frequency \\
\hline semi & If the rectifier is 3-phase half controlled its 1 else it is 0 \\
\hline ia & If the input is iawt or itwt it is 1 else is 0 \\
\hline $\mathrm{n}$ & The number of desired harmonics \\
\hline
\end{tabular}

Table 6. Output variables of "rectfour.m" m-file.

\begin{tabular}{|l|l|}
\hline Output Variable & Description \\
\hline Dc & Input wave dc value \\
\hline $\mathrm{a}$ & The vector of “a" coefficient in Fourier series \\
\hline $\mathrm{b}$ & The vector of "b" coefficient in Fourier series \\
\hline mag & The vector of harmonics' magnitude \\
\hline phase & The vector of harmonics' phase \\
\hline ff & The vector of harmonics' frequency \\
\hline c1 & $1 / \sqrt{a_{1}^{2}+b_{1}^{2}}$ \\
\hline cn & $\sum_{i=1}^{N} c_{i}$ \\
\hline Ph1 & Arctan(a1/b1) in order to calculate efficiency parameters \\
\hline maximum & The maximum value of input vector \\
\hline
\end{tabular}

\section{- M-file for Rectifier Efficiency Parameters Calculation}

The name of m-file is "rectparam.m" and its general format is as below in which inputs are identical to "rectifier.m" function and the outputs are according to [15].

[Vav, Vrms, Vac, Iav, Irms A, IrmsA, Is, Is1, Ismax , Pdc, Pac, P, Eta, FF, RF, TUF, DF, HF, PF, CF] = rect param $(v m, R, L, E, f, a, T$, Ihold, diode, $n)$

\section{RECTSIM INTERACTIVE PROGRAM}

According to introduced $\mathrm{m}$-files, rectsim interactive program is developed by utilizing GUI abilities in MATLAB software. In order to run the program, it is enough to download proper files, containing mentioned $\mathrm{m}$-files, from the internet and address them in the path of MATLAB software. Then by running "rectsim" instruction in command line of MATLAB, the program will be run and its environment will be seen as Figure 6. 


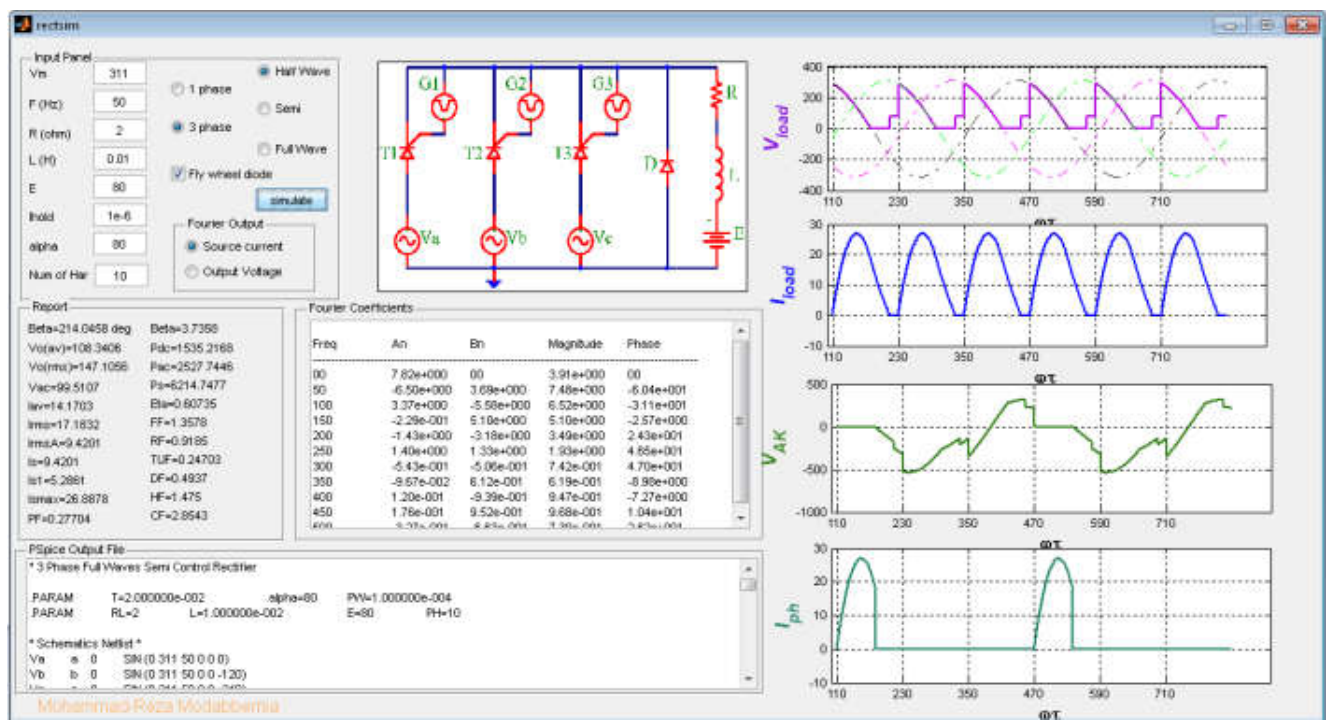

Figure 6. environment of "rectsim" interactive program

Utilizing this program has two prominent advantages; first, it is straightforward, so students do not deal with different sections of programming environment. Second, only by entering some digits and pressing a button, it is available to see all important output waveforms, efficiency parameter, load current and load voltage harmonics and PSpice output netlist file.

Conversely, in Spice-based electronic software or in PowerSim environment of MATLAB, to simulate each kind of rectifiers a different file should be run and the information of each rectifier should be altered individually. This not only reduces the speed and efficiency of instructing in the class, but also reduces the threshold of students' tolerance. Further, watching the output results in this software needs an enough level of competency in order to adjust different parameters of software. Giving improper value to any parameter results in inaccurate response that is not convenient for education. But working with "rectism" is very simple and it can also produce a netlist file with defined parameters of rectifier, in ".cir" format, that is needed for PSpice program. This text file can be seen in program environment and can be simulated in Pspice A/D program. As it can be seen in Figure 2, proposed software environment has six sections; 1- Input panel 2Circuit schematic display 3- Outputs waveform display 4- Report 5- Fourier Coefficients and 6- PSpice output file

By means of input panel, operator can enter desired input values and select existed choices in order to define rectifier type, load value, type a number of output harmonics. Then the circuit schematic is displayed in adjacent section. After input definition by clicking on simulate button simulating the given circuit, four output waveforms will be displayed in right column of the software including; load voltage, load current, thyristor no. 1 voltage and current of phase a. All waveforms start from Gate firing angle of thyristor no.1. In report section turn-off angle of thyristor no.1, average 
voltage and current, effective voltage and current and efficiency parameters of rectifier will be displayed in numerical format. In middle window, Fourier coefficients will be given as $a_{i}, b_{i}$, "mag" and "phase". Finally, in the below section of Figure 2 the netlist file (.cir) of PSpice will be given. It should be mentioned that according to any changes in input value, defined by operator, PSpice netlist changes automatically.

\section{SIMULATION OF POWER ELECTRONIC RECTIFIER CIRCUITS}

In this section some rectifiers' circuits analyzed in reference books are simulated by proposed program and PSpice software in order to evaluate the capabilities of our program in analysis of applicable circuits and also its feasibility in educational curriculums.

Variation of rectifiers' types and their loads that result in continuity or discontinuity of current, can lead to a mistaken analysis presented in reference books. Some samples of these mistakes can be traced by software simulation. This can be another fact that can help instructor and student in order to prevent such probable mistakes which are referred in section III and Figure 1. In this work, it is believed that very first step in rectifier circuit analysis is the definition of continuity or discontinuity of load current that in turn, should be define with respect to rectifier type, $\alpha$ and $\beta$. The proposed software will define these parameters by numerical value and waveforms based on an accurate theory that remarkably helps improving students' perception. As it can be seen in further sub-sections, all sample simulation output waveforms are presented to the accompaniment of numerical values of these parameters.

\subsection{Controlled single- Phase Full- wave Rectifier}

In the example 5-5 from [18], a full-wave convertor with single-phase $120 \mathrm{~V}$ effective voltage and $60 \mathrm{~Hz}$ frequency input source is loaded by a combination of $E=10 \mathrm{~V}, L=6.5 \mathrm{mH}$ and $R=0.5 \Omega$ and is fired by gate firing angle of $\alpha=60^{\circ}$. This circuit is simulated by the presented program and PSpice software. The output waveforms and the Fourier coefficients results are shown in Figures 7(a) and 7(b) and Figures 8(a) and 8(b) respectively. Also a comparison is made by listing the obtained output parameters in Table 7 resulted from reference book, PSpice simulation and presented software simulation.

Table 7. Comparision amoung obtained output parameters of example of section 5.1

\begin{tabular}{|l|l|l|l|l|l|}
\hline & $V_{a v}$ & $V_{r m s}$ & $I_{a v}$ & $I_{r m s}$ & $\beta$ \\
\hline$[18]$ results & $54.02 \mathrm{~V}$ & --- & $88.01 \mathrm{~A}$ & $90.1 \mathrm{~A}$ & $\begin{array}{l}\text { Continuous } \\
\text { load current }\end{array}$ \\
\hline $\begin{array}{l}\text { Presented } \\
\text { program results }\end{array}$ & $54.017 \mathrm{~V}$ & $119.99 \mathrm{~V}$ & $88.03 \mathrm{~A}$ & $90.07 \mathrm{~A}$ & $258.8^{\circ}$ \\
\hline
\end{tabular}




\begin{tabular}{|l|l|l|l|l|l|}
\hline PSpice results & $54.04 \mathrm{~V}$ & $118.22 \mathrm{~V}$ & $80.078 \mathrm{~A}$ & $82.3 \mathrm{~A}$ & $\begin{array}{l}\text { Continuous } \\
\text { load current }\end{array}$ \\
\hline
\end{tabular}

\subsection{Controlled Three- Phase Full- wave Rectifier}

Here, the example 5-5 from [19] which is a full-wave three-phase rectifier fed by $60 \mathrm{~Hz}, 230 \mathrm{~V}$ effective line voltage source and loaded with a combination of $E=200 \mathrm{~V}, L=5 \mathrm{mH}$ and $R=0.8 \Omega$ accompanied by gate firing angle of $\alpha=30^{\circ}$, is simulated. Obtained output parameters from reference book, PSpice simulation and presented Program simulation are listed in Table 8. In order to make a comparison among their results, Figures 9(a) and 9(b) illustrates output waveforms of presented and PSpice software. In addition, Figures 10(a) and 10(b) shows Fourier series coefficient from simulation of mentioned circuit in these two softwares.

Table 8. Comparision amoung obtained output parameters of example of section 5.2

\begin{tabular}{|c|c|c|c|c|c|}
\hline & $V_{a v}$ & $V_{r m s}$ & $I_{a v}$ & $I_{r m s}$ & $\beta$ \\
\hline [19] results & $269 \mathrm{~V}$ & -- & $86.2 \mathrm{~A}$ & $86.3 \mathrm{~A}$ & $\begin{array}{c}\text { Continuous load } \\
\text { current }\end{array}$ \\
\hline $\begin{array}{c}\text { Presented } \\
\text { program results }\end{array}$ & $268.99 \mathrm{~V}$ & $273.45 \mathrm{~V}$ & $86.24 \mathrm{~A}$ & $86.32 \mathrm{~A}$ & $145.75^{\circ}$ \\
\hline Pspice results & $267.72 \mathrm{~V}$ & $272.29 \mathrm{~V}$ & $84.71 \mathrm{~A}$ & $84.79 \mathrm{~A}$ & $\begin{array}{c}\text { Continuous load } \\
\text { current }\end{array}$ \\
\hline
\end{tabular}

\subsection{Half-Wave Controlled Three- Phase Rectifier}

In example 9-5 from [18], a three-phase half-wave controlled-rectifier is fed by line effective voltage of $208 \mathrm{~V}$ and frequency of $60 \mathrm{~Hz}$. This convertor's load is a pure Ohmic resistance with the value of $R=10 \Omega$. By applying firing angle of $\alpha=90^{\circ}$ the output obtained parameters are shown in Table 9. Simulating given circuit in proposed program and Pspice software, output wave forms of Figures 11(a) and 11(b) are obtained. Attained harmonics from these two software simulation can be seen in Figures 12(a) and 12(b). Table 9 depicts a comparison among output efficiency parameters of these simulations. 


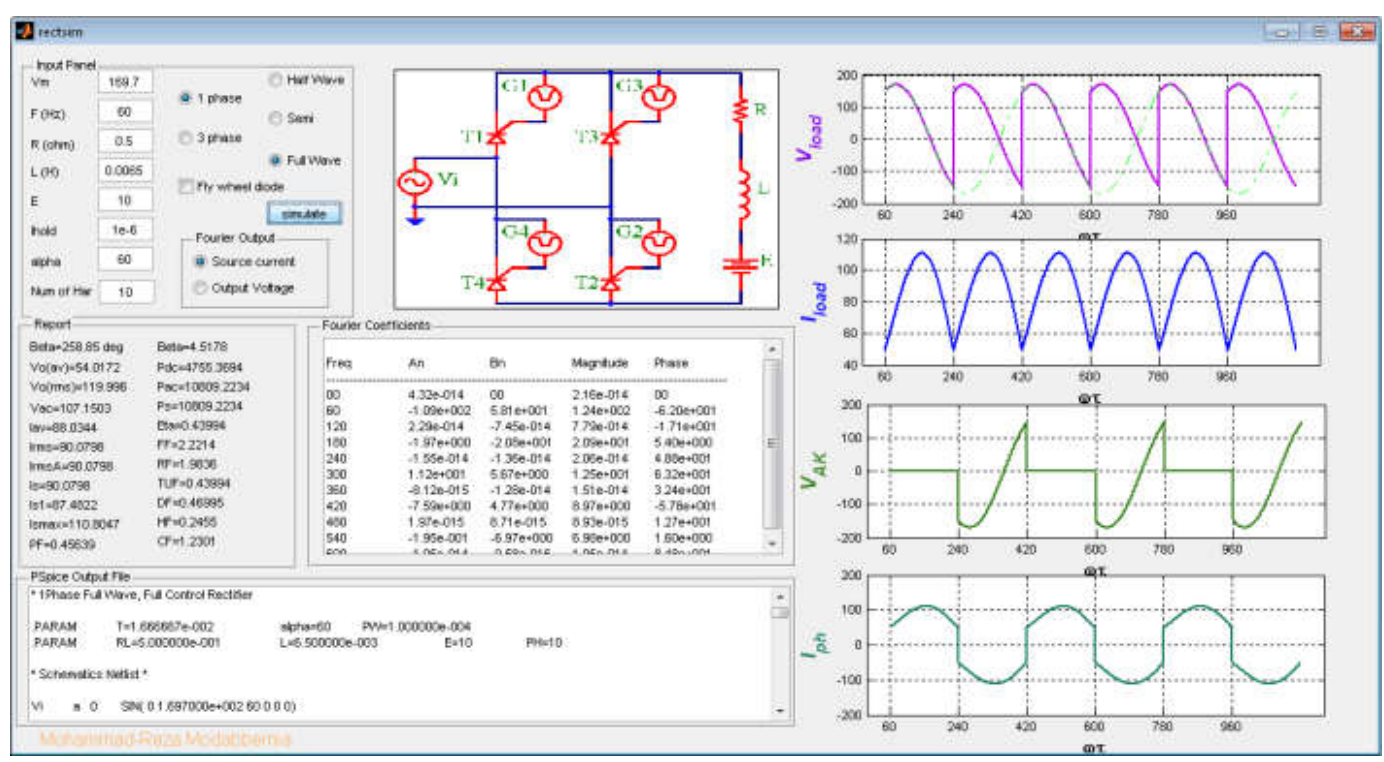

(a) Presented Program

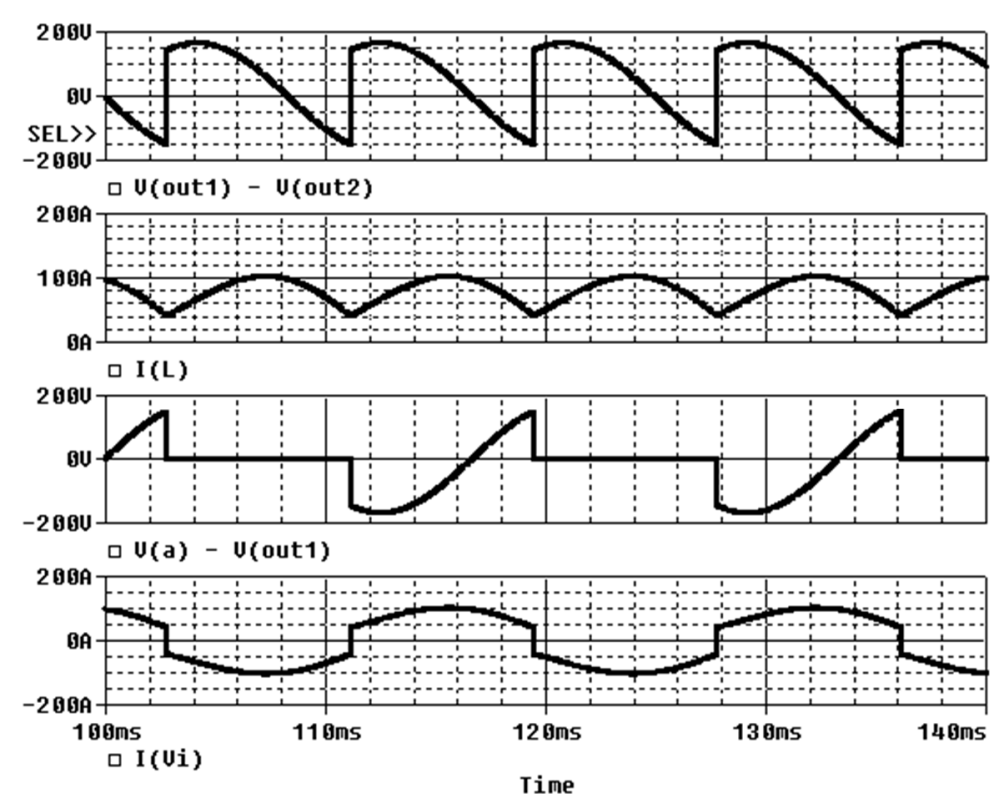

(b) PSpice software

Figure 7. Output waveforms of example of section 5.1. 


\begin{tabular}{llll} 
Freq & An & Bn & Magnitude \\
\hline 00 & $4.32 \mathrm{e}-014$ & 00 & $2.16 \mathrm{e}-014$ \\
60 & $-1.09 \mathrm{e}+002$ & $5.81 \mathrm{e}+001$ & $1.24 \mathrm{e}+002$ \\
120 & $2.29 \mathrm{e}-014$ & $-7.45 \mathrm{e}-014$ & $7.79 \mathrm{e}-014$ \\
180 & $-1.97 \mathrm{e}+000$ & $-2.08 \mathrm{e}+001$ & $2.09 \mathrm{e}+001$ \\
240 & $-1.55 \mathrm{e}-014$ & $-1.36 \mathrm{e}-014$ & $2.06 \mathrm{e}-014$ \\
300 & $1.12 \mathrm{e}+001$ & $5.67 \mathrm{e}+000$ & $1.25 \mathrm{e}+001$ \\
360 & $-8.12 \mathrm{e}-015$ & $-1.28 \mathrm{e}-014$ & $1.51 \mathrm{e}-014$ \\
420 & $-7.59 \mathrm{e}+000$ & $4.77 \mathrm{e}+000$ & $8.97 \mathrm{e}+000$ \\
480 & $1.97 \mathrm{e}-015$ & $8.71 \mathrm{e}-015$ & $8.93 \mathrm{e}-015$ \\
540 & $-1.95 \mathrm{e}-001$ & $-6.97 \mathrm{e}+000$ & $6.98 \mathrm{e}+000$
\end{tabular}

(a) Presented Program

DC COMPONENT $=4.110601 \mathrm{E}-01$

$\begin{array}{ccc}\begin{array}{c}\text { HARMONIC } \\ \text { NO }\end{array} & \begin{array}{c}\text { FREQUENCY } \\ \text { (HZ) }\end{array} & \begin{array}{c}\text { FOURIER } \\ \text { COMPONENT }\end{array} \\ 1 & 6.000 \mathrm{E}+01 & 1.136 \mathrm{E}+02 \\ 2 & 1.200 \mathrm{E}+02 & 8.227 \mathrm{E}-01 \\ 3 & 1.800 \mathrm{E}+02 & 1.760 \mathrm{E}+01 \\ 4 & 2.400 \mathrm{E}+02 & 8.237 \mathrm{E}-01 \\ 5 & 3.000 \mathrm{E}+02 & 1.058 \mathrm{E}+01 \\ 6 & 3.600 \mathrm{E}+02 & 8.261 \mathrm{E}-01 \\ 7 & 4.200 \mathrm{E}+02 & 7.567 \mathrm{E}+00 \\ 8 & 4.800 \mathrm{E}+02 & 8.296 \mathrm{E}-01 \\ 9 & 5.400 \mathrm{E}+02 & 5.893 \mathrm{E}+00\end{array}$

(b) PSpice software

Figure 8. Fourier coefficients of example of section 5.1.

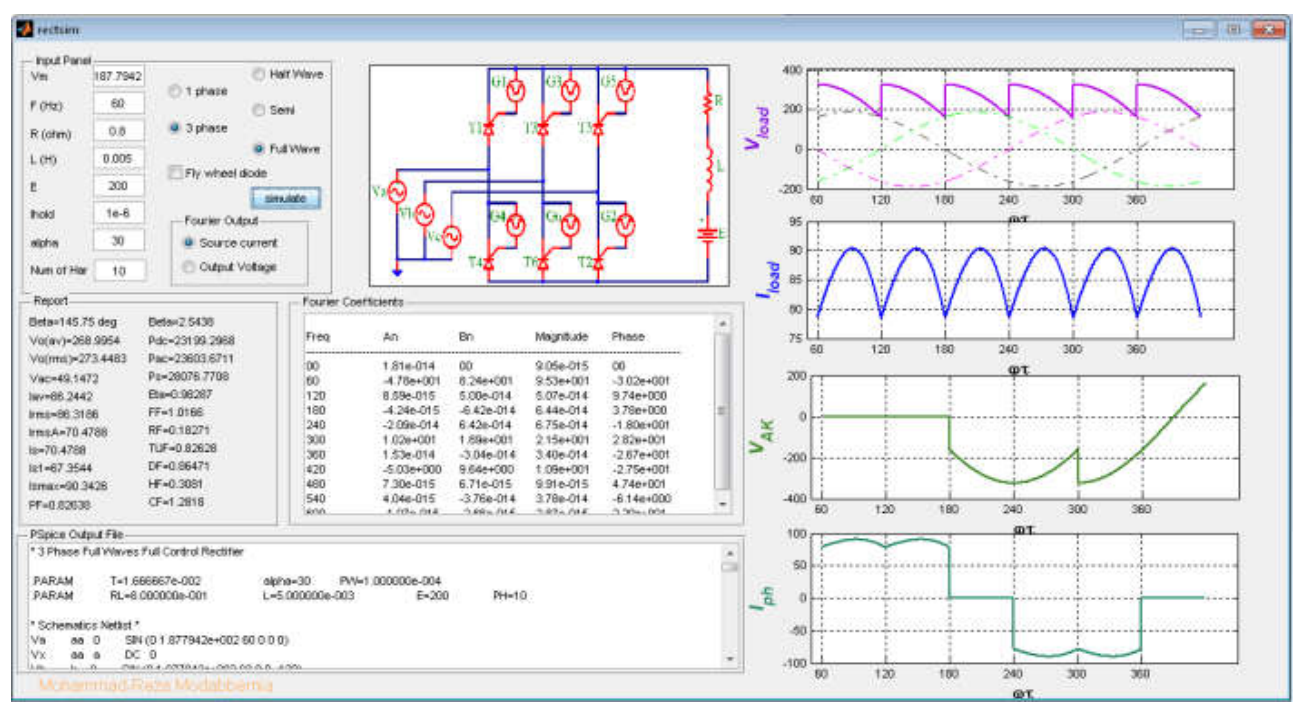

(a) Presented Program

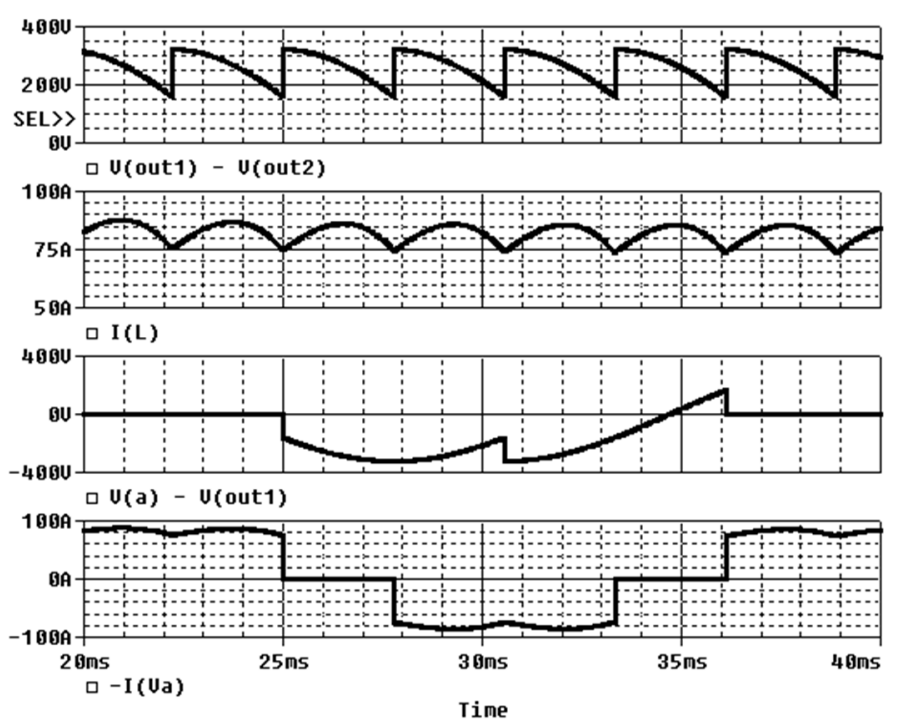

(b) PSpice software

Figure 9. Output waveforms of example of section 5.2. 


\begin{tabular}{llll} 
Freq & An & Bn & Magnitude \\
\hline 00 & $1.81 \mathrm{e}-014$ & 00 & $9.05 \mathrm{e}-015$ \\
60 & $-4.78 \mathrm{e}+001$ & $8.24 \mathrm{e}+001$ & $9.53 \mathrm{e}+001$ \\
120 & $8.59 \mathrm{e}-015$ & $5.00 \mathrm{e}-014$ & $5.07 \mathrm{e}-014$ \\
180 & $-4.24 \mathrm{e}-015$ & $-6.42 \mathrm{e}-014$ & $6.44 \mathrm{e}-014$ \\
240 & $-2.09 \mathrm{e}-014$ & $6.42 \mathrm{e}-014$ & $6.75 \mathrm{e}-014$ \\
300 & $1.02 \mathrm{e}+001$ & $1.89 \mathrm{e}+001$ & $2.15 \mathrm{e}+001$ \\
360 & $1.53 \mathrm{e}-014$ & $-3.04 \mathrm{e}-014$ & $3.40 \mathrm{e}-014$ \\
420 & $-5.03 \mathrm{e}+000$ & $9.64 \mathrm{e}+000$ & $1.09 \mathrm{e}+001$ \\
480 & $7.30 \mathrm{e}-015$ & $6.71 \mathrm{e}-015$ & $9.91 \mathrm{e}-015$ \\
540 & $4.04 \mathrm{e}-015$ & $-3.76 \mathrm{e}-014$ & $3.78 \mathrm{e}-014$
\end{tabular}

$\begin{array}{ccc}\text { DC COMPONENT }= & 1.496033 \mathrm{E}-02 \\ \begin{array}{c}\text { HARMONIC } \\ \text { FO }\end{array} & \begin{array}{c}\text { FREUENCY } \\ \text { (HZ) }\end{array} & \begin{array}{c}\text { FOURIER } \\ \text { COMPONENT }\end{array} \\ & & \\ 1 & 6.000 \mathrm{E}+01 & 9.077 \mathrm{E}+01 \\ 2 & 1.200 \mathrm{E}+02 & 1.559 \mathrm{E}+00 \\ 3 & 1.800 \mathrm{E}+02 & 1.121 \mathrm{E}+00 \\ 4 & 2.400 \mathrm{E}+02 & 1.230 \mathrm{E}+00 \\ 5 & 3.000 \mathrm{E}+02 & 2.012 \mathrm{E}+01 \\ 6 & 3.600 \mathrm{E}+02 & 7.443 \mathrm{E}-02 \\ 7 & 4.200 \mathrm{E}+02 & 1.064 \mathrm{E}+01 \\ 8 & 4.800 \mathrm{E}+02 & 1.181 \mathrm{E}+00 \\ 9 & 5.400 \mathrm{E}+02 & 9.674 \mathrm{E}-01\end{array}$

(a) Presented Program

(b) Pspice software

Figure 10. Fourier coefficients of example of section 5.2.

Table 9. Comparision amoung obtained output parameters of example of section 5.3

\begin{tabular}{|c|c|c|c|c|c|}
\hline & $V_{a v}$ & $V_{r m s}$ & $I_{a v}$ & $I_{r m s}$ & $\beta$ \\
\hline$[18]$ results & $140.45 \mathrm{~V}$ & $180.13 \mathrm{~V}$ & $14.05 \mathrm{~A}$ & $18.01 \mathrm{~A}$ & --- \\
\hline $\begin{array}{c}\text { Presented program } \\
\text { results }\end{array}$ & $140.45 \mathrm{~V}$ & $180.133 \mathrm{~V}$ & $14.05 \mathrm{~A}$ & $18.01 \mathrm{~A}$ & $210^{\circ}$ \\
\hline Pspice results & $138.89 \mathrm{~V}$ & $178.216 \mathrm{~V}$ & $13.91 \mathrm{~A}$ & $17.85 \mathrm{~A}$ & $210^{\circ}$ \\
\hline
\end{tabular}

\section{CONCLUSION}

Technology development, in the field of communication accompanied by computer programs tendency to utilize object-oriented capabilities, not only has been led to alteration of program resemblance, but also it has provided capacities and facilities in order to present new educational methods.

In this paper, based on GUI capabilities in MATLAB, an interactive program had been proposed to simulate all kinds of single or three-phase ac to dc converters in presence of each combination of $\mathrm{R}, \mathrm{L}$ and $\mathrm{E}$ loads. This program can be operated to illustrate rectifiers' operation mechanism in the classes, virtual education, education through distance learning and primary design or analysis of practical circuits in power electronic laboratories.

The proposed program is very small in volume and has a very simple execution environment that can be easily downloaded from the internet and applied in MATLAB in order to be run. Alteration in circuit and load types can be simply done without any special expertise of an operator and the related results can be easily observed by a simple click. Provided outputs are current and voltage waveforms, efficiency parameters of rectifier, output harmonics and finally ".cir" netlist file related to simulated circuit applicable in PSpice.

Another prominent advantage of the presented program in educational situation is that it is prepared based on theoretical foundation and curriculums 
that can be offered in the classes so that students can simply check their paperbased-solution methods with the simple and fast simulation outputs of the program in order to correct their homework or make a proper revision.

\section{Acknowledgements} IRAN.

This work is supported by Technical and Vocational University, Tehran,

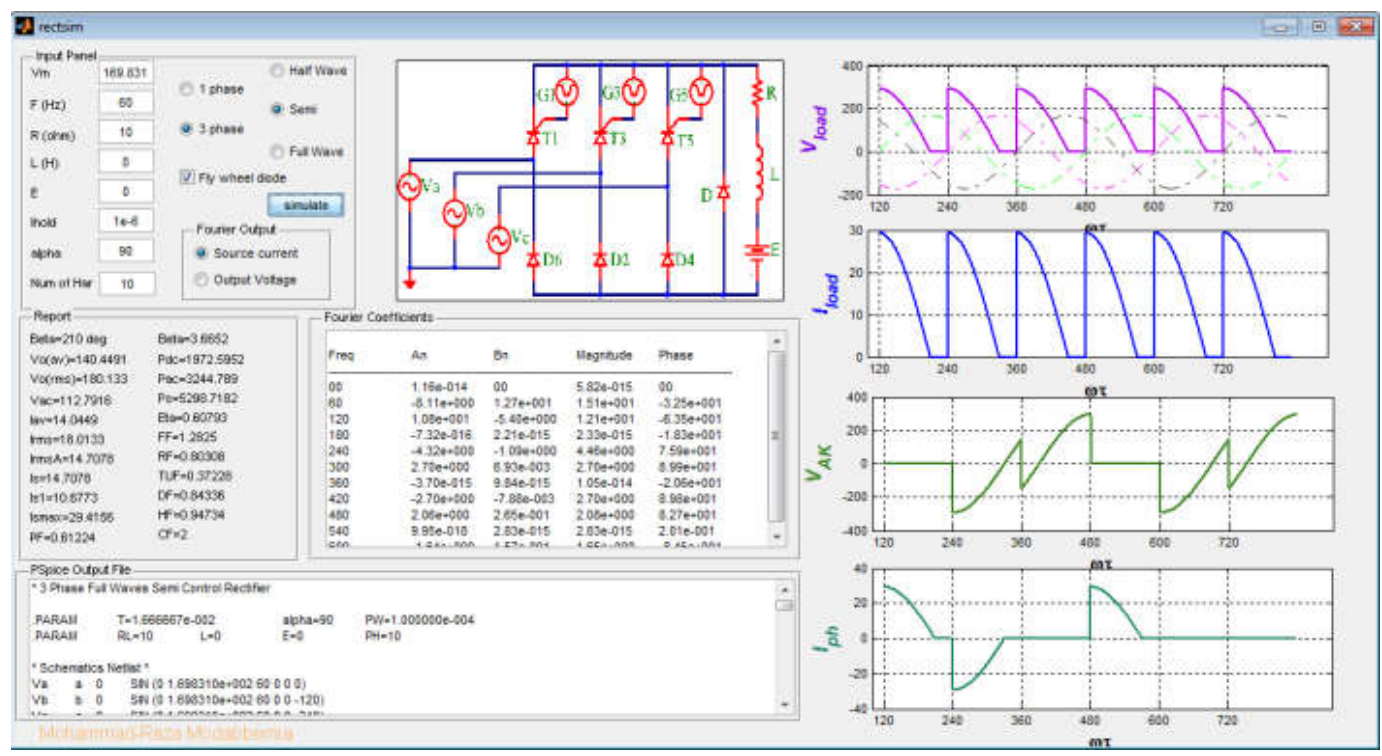

(a) Presented Program

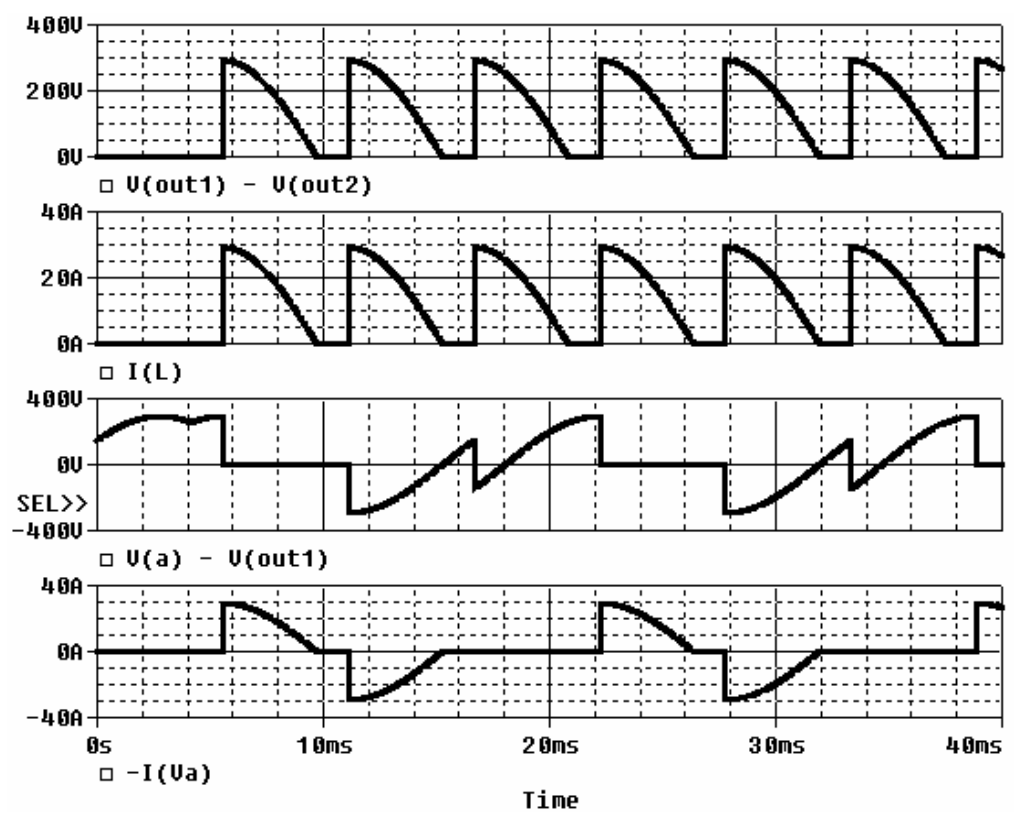

(b) Pspice software

Figure 11. Output waveforms of example of section 5.3. 


\begin{tabular}{llll} 
Freq & An & Bn & Magnitude \\
\hline 00 & $1.16 \mathrm{e}-014$ & 00 & $5.82 \mathrm{e}-015$ \\
60 & $-8.11 \mathrm{e}+000$ & $1.27 \mathrm{e}+001$ & $1.51 \mathrm{e}+001$ \\
120 & $1.08 \mathrm{e}+001$ & $-5.40 \mathrm{e}+000$ & $1.21 \mathrm{e}+001$ \\
180 & $-7.32 \mathrm{e}-016$ & $2.21 \mathrm{e}-015$ & $2.33 \mathrm{e}-015$ \\
240 & $-4.32 \mathrm{e}+000$ & $-1.09 \mathrm{e}+000$ & $4.46 \mathrm{e}+000$ \\
300 & $2.70 \mathrm{e}+000$ & $6.93 \mathrm{e}-003$ & $2.70 \mathrm{e}+000$ \\
360 & $-3.70 \mathrm{e}-015$ & $9.84 \mathrm{e}-015$ & $1.05 \mathrm{e}-014$ \\
420 & $-2.70 \mathrm{e}+000$ & $-7.88 \mathrm{e}-003$ & $2.70 \mathrm{e}+000$ \\
480 & $2.06 \mathrm{e}+000$ & $2.65 \mathrm{e}-001$ & $2.08 \mathrm{e}+000$ \\
540 & $9.95 \mathrm{e}-018$ & $2.83 \mathrm{e}-015$ & $2.83 \mathrm{e}-015$ \\
600 & $-1.64 \mathrm{e}+000$ & $1.57 \mathrm{e}-001$ & $1.65 \mathrm{e}+000$
\end{tabular}

(a) Presented Program

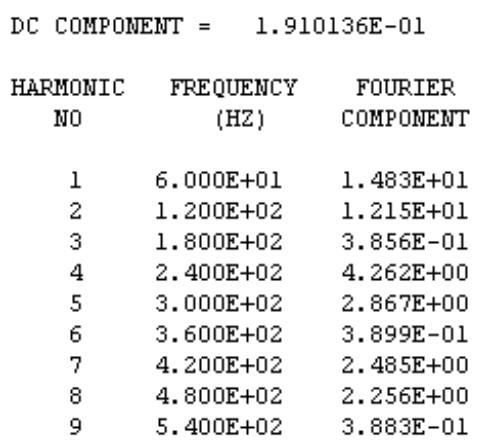

(b) PSpice software

Figure 12. Fourier coefficients of example of section 5.3 .

\section{REFERENCES}

[1] G. Hwang, A tutoring strategy supporting system for distance learning on computer networks, IEEE Trans. Educ., vol. 41, no. 4, pp. 343-343, Nov. 1998.

[2] L. T. Pillage, An Early Introduction to Circuit Simulation Techniques, IEEE Transaction on Education, vol. 36, no. 1, pp. 16-19, FEB 1993.

[3] G. Bengu and W. Swart, A computer-aided, total quality approach to manufacturing education in engineering, IEEE Transaction on Education, vol. 39, no. 3, pp. 415-422, Aug. 1996.

[4] M. H. Rashid and S. A. AL-Biyat, Power Electronics Laboratory Using Pspice, Frontiers in Education, 26 ${ }^{\text {th }}$ Annual Conference, vol. 2, pp. 534-537, 1996.

[5] L. J. Giacoletto, Simple SCR and Triac Pspice Computer Models, IEEE Transaction on Industerial Electronics, vol. 36, no. 3, pp.451-455, AUGUST 1989.

[6] V. Agrawal, A. Agraval and K. kant, A Study of Single to Three-Phase Cycloconverters Using PSpice, IEEE Transaction on Industrial Electronics, vol. 39, no. 2, pp. 141-148, APRIL 1992.

[7] D. W. Hart, Circuit Simulation as an Aid in Teaching the Principles of power Electronics, IEEE Transaction on Education, vol. 36, no.1, pp, 10-16, FEB 1993.

[8] L. A. Dessaint, K. AL-Haddad, H. L. Huy, G. Sybille and P. Brunelle, A Power System Simulation Tool Based on Simulink, IEEE Transaction on Industrial Electronics, vol.46, no.6, DECEMBER 1999.

[9] V. Ramaswamy, Power electronics online text, Oct. 23, 2009, Available:

http://services.eng.uts.edu.au/ venkat/pe html/peintro.htm

[10] U. Drofenik and J. W. Kolar, Interactive power electronics seminar(iPES)-a Web-based introductory power electronics course employing Java applets, in Proc. IEEE Annu. Power Electron. Specialists Conf., Cairns, Australia, 2002, vol. 2, pp. 443-448. 
[11] M. H. Todorovic, L. Palma, and P. Enjeti, Development of new Webbased materials to teach power electronics courses, in Proc. IEEE Power Electron. Educ. Workshop, Recife, Brazil, 2005, vol. 1, pp. 9-14.

[12] P. Bauer, B. Davat, V. Fedak, and V. Hajek, Educational visualization for teaching power electronics, in Proc. IEEE Power Electron. Educ. Workshop, Recife, Brazil, 2005, vol. 1, pp. 45-51.

[13] S. Harb, K. Kalaldeh, A. Harb, and I. Batarseh, Interactive Java applets for power electronics e-learning, in Proc. IEEE Power Electron. Educ. Workshop, Recife, Brazil, 2005, vol. 1, pp. 26-33.

[14] C. A. Canesin, F. A. S. Goncalves, and L. P. Sampaio, Simulation Tools for Power Electronics Courses Based on Java Technologies, IEEE Transaction on Education, vol. 53, no. 4, pp. 580-586, Nov. 2010.

[15] J.M. Flores-Arias, A. Moreno-Munoz, F. J. Bellido, and M. Linan, Active learning in power electronics: From classroom to laboratory, IEEE EDUCON 2010 Conference. IEEE, 2010.

[16] U. Drofenik, A. Müsing, and J. W. Kolar, Novel online simulator for education of power electronics and electrical engineering, The 2010 International Power Electronics Conference-ECCE ASIA-. IEEE, 2010.

[17] F. J. Maseda, I. Martija, and I. Martija, An active learning methodology in power electronic education, 2014 IEEE Frontiers in Education Conference (FIE) Proceedings. IEEE, 2014.

[18] M. H. Rashid, Power electronics - Circuits, Devices and Applications, Prentice-Hall, Second Edition, 1993.

[19] S. R. Deawan, and A. Straughen, Power Semiconductor Circuits, John Wiley \& Sons. 1975. 